\title{
The analysis of instantaneous tool displacements during precise ball end milling
}

\author{
Szymon Wojciechowski ${ }^{1, *}$ \\ ${ }^{1}$ Poznan University of Technology, Faculty of Mechanical Engineering and Management, Institute of \\ Mechanical Technology, Poznan, Poland
}

\begin{abstract}
The paper presents the quantitative and qualitative analysis of monolithic ball end mill's instantaneous displacements generated during precise milling of inclined surfaces. The conducted experiment involves the measurements of tool's joining part displacements with the application of laser displacement sensor and cutting forces with piezoelectric dynamometer. The milling tests were carried out for the hardened alloy $55 \mathrm{NiCrMoV} 6$ steel in a range of variable feed per tooth and surface inclination angle values. The obtained results can be applied for the selection of effective milling parameters allowing the improvement of machined surface finish.
\end{abstract}

\section{Introduction}

The high machined surface quality is the fundamental requirement regarding the precise ball end milling process. It is usually depended on the selected milling parameters, as well as the specific machine-milling process interactions. The literature survey shows that geometrical product's specification (GPS) obtained after machining process is strongly affected by the cutting parameters [1], dynamical stability [2], thermal phenomena in the machining zone [3], as well as the ploughing mechanisms correlated with the minimum uncut chip thickness $[4,5]$. Nevertheless, apart from the above-mentioned factors, the toolworkpiece vibrations (periodical displacements) can be also the critical quantity affecting the machined surface finish $[6,7]$.

The instantaneous tool displacements generated during milling process are usually induced by the geometrical errors (e.g. run out) and dynamic properties (e.g. damping, stiffness) of machine-toolholder-tool system [8,9]. Moreover, in case of a ball end milling process, the variations of surface inclination angle along the toolpath cause the changes in tool's effective cutting speed and thus significantly affect the process dynamics [10]. Therefore, the identification of the crucial factors influencing the tool's instantaneous displacements during milling is important in terms of machined surface quality improvement. However the accurate on-line measurement of tool's displacement during precise milling is a difficult task because of the inhibited access to the tool's working part, chip formation phenomenon and tool's rotational motion distorting the measured signals. Thus, the vibrations are usually measured with the application of indirect methods which

\footnotetext{
${ }^{*}$ Corresponding author: sjwojciechowski@o2.pl
} 
involve the use of accelerometers fixed to the spindle head or workpiece. However the acquired signals require post-processing, including the filtration and integration, as well as they are not fully compatible with the real tool's displacement. Therefore, recently the novel, non-contact on-line measurement methods of tool's instantaneous displacements, based on laser vibrometry, capacitive gap sensors and laser displacement sensors have been developed.

Tatar and Gren [11] applied the scanning laser vibrometer (LDV) for the measurements of indexable 2-toothed mill's displacements during milling of AA7010 aluminum alloy. The similar approach has been adopted by Wojciechowski et al. [12] for the on-line measurements of 6-toothed end mill's joining part displacements during milling of hardened alloy steel. Miyaguchi et al. [13] carried out the measurements of ball end mill's instantaneous displacement with the application of capacitive gap sensor during cutting of hardened steel.

The state-of-the-art shows that despite a few researches, the problem of tool's instantaneous displacement evaluation during precise milling is still insufficiently recognized. Therefore this work focuses on the quantitative and qualitative analysis of ball end mill's instantaneous displacements generated during precise ball end milling of inclined surfaces. The carried out measurements involve the application of laser displacement sensor. The obtained results can contribute to the better understanding of the phenomena occurring during the GPS formation in milling process, and consequently to the selection of effective milling parameters enabling the improvement of surface finish.

\section{Experiment}

\subsection{Workpiece and tool}

The experiments have been carried out on hardened alloy steel 55NiCrMoV6 sample with average hardness of $52 \mathrm{HRC}$. The chemical composition of the work material is presented in table 1. The selected tool was monolithic ball end mill made of fine-grained sintered tungsten carbide (WC) with diameter $D=10 \mathrm{~mm}$ and number of teeth $z=2$. The tool's geometry was as follows: $\gamma_{o}=-10^{\circ}, \lambda_{s}=30^{\circ}, \alpha_{o}=6^{\circ}$. The ball end mill has been clamped in a HSK-63 shrink fit toolholder. The selection of this toolholder was dictated by its recommendation to High Speed Milling technology, because of high dynamical balancing. Experiments were carried out on 5-axes CNC milling workstation.

Table 1. The chemical composition of the 55NiCrMoV6 steel.

\begin{tabular}{|c|c|c|c|c|c|c|}
\hline $\mathrm{C}$ & $\mathrm{Si}$ & $\mathrm{Mn}$ & $\mathrm{Cr}$ & $\mathrm{Mo}$ & $\mathrm{Ni}$ & $\mathrm{V}$ \\
\hline $0.5-0.6 \%$ & $0.1-0.4 \%$ & $0.65-0.95 \%$ & $0.6-0.8 \%$ & $0.25-0.35 \%$ & $1.5-1.8 \%$ & $0.07-0.12 \%$ \\
\hline
\end{tabular}

\subsection{Research range and method}

Milling tests included the measurement of ball end mill's instantaneous displacements and cutting force components, conducted in the range of variable surface inclination angles $\alpha$ and feed per tooth $f_{z}$. In order to obtain surface inclination during the milling process, tool's rotational axis was inclined against the workpiece in the range of various $\alpha$ angles (Fig. 1). 


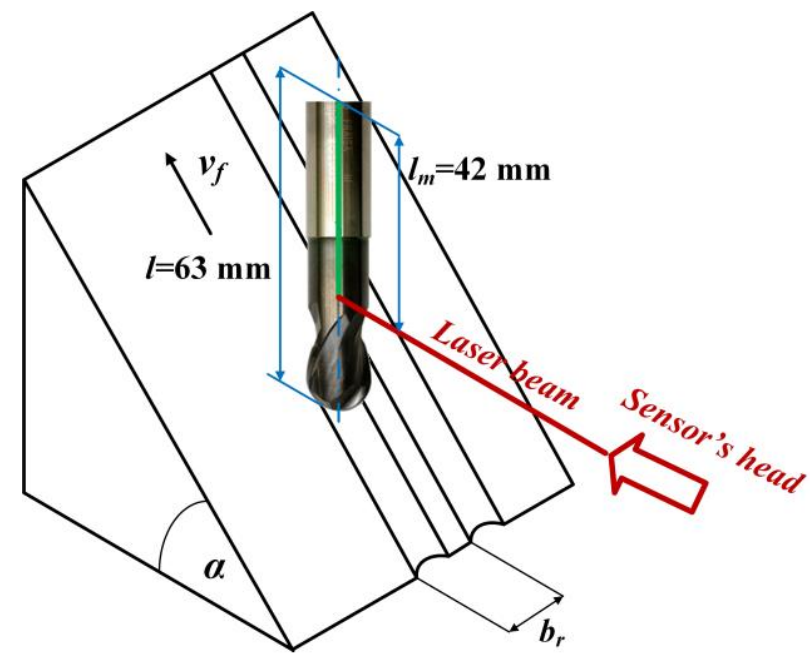

Fig. 1. Ball end milling kinematics and measurement of tool displacement.

In all investigated cases tool's effective diameter was lower than the value of pick feed $-D_{e f}<b_{r}$. The milling parameters applied in the research were depicted in table 2 .

Table 2. Design of experiment.

\begin{tabular}{|c|c|c|c|c|c|}
\hline $\begin{array}{c}\text { Cutting speed } \\
v_{c}[\mathrm{~m} / \mathrm{min}]\end{array}$ & $\begin{array}{c}\text { Depth of } \\
\text { cut } \\
a_{p}[\mathrm{~mm}]\end{array}$ & $\begin{array}{c}\text { Rotational } \\
\text { speed } n \\
{[\mathrm{rev} / \mathrm{min}]}\end{array}$ & $\begin{array}{c}\text { Inclination angle } \\
\alpha\left[^{\circ}\right]\end{array}$ & $\begin{array}{c}\text { Feed per tooth } \\
f_{z}[\mathrm{~mm} / \text { tooth }]\end{array}$ & $\begin{array}{c}\text { Overhang } \\
l[\mathrm{~mm}]\end{array}$ \\
\hline 200 & 0.3 & $7351-$ & $0-60$ & $0.05-0.2$ & 63 \\
& & 18614 & 20 interval & 0.05 interval & \\
\hline
\end{tabular}

The cutting force components were measured in the three directions $\left(F_{x}[\mathrm{~N}]-\right.$ feed normal direction, $F_{y}[\mathrm{~N}]$ - feed direction, $F_{z}[\mathrm{~N}]$ - thrust direction) with the application of the 3-directional piezoelectric sensor (Fig. 2).

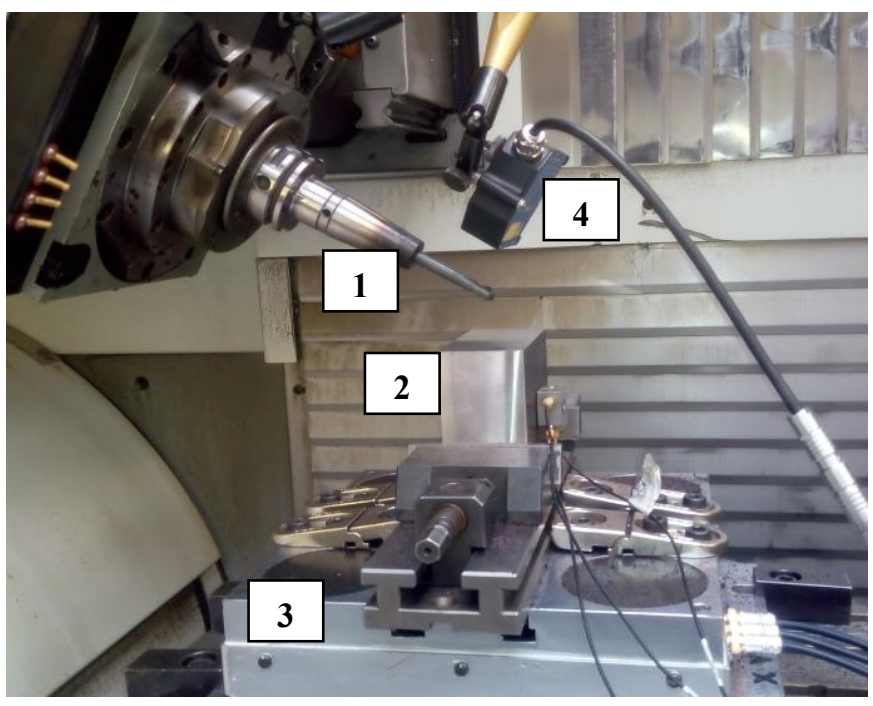

Fig. 2. The experimental set-up for the on-line measurement of forces and tool displacements $(1-$ ball end mill-toolholder system, 2 - workpiece, 3 - force dynamometer, 4 - laser displacement sensor). 
The force dynamometer was connected through amplifiers and band-pass filters to a data acquisition computer. The acquisition of signals was made with the application of dedicated software. This software was applied also for the calculation of signal's root mean square (RMS) values and filtration carried out with a low-pass filter.

The optoNCDT Micro-Epsilon laser sensor has been applied for the on-line measurements of ball end mill's instantaneous displacements (Fig. 2) in the direction perpendicular to the tool's rotational axis and collinear to the feed motion vector (Fig. 1). The laser's beam wavelength was $\lambda=670 \mathrm{~nm}$, the measuring range was $10 \mathrm{~mm}$ and FSO (full-scale output) resolution at sampling frequency of $2500 \mathrm{~Hz}$ was equaled to $0.5 \mu \mathrm{m}$. The acquired signal has been filtered with the application of software low-pass Chebyshev's filter in order to eliminate the undesirable distortions. The cut off frequency $f_{c}$ was determined on the basis of the following expression:

$$
f_{c} \approx \frac{z \cdot n}{30}+10 \%
$$

\section{Results and discussion}

The figure 3 depicts the measured instantaneous values of ball end mill displacements in function of surface inclination angle $\alpha$ and feed per tooth $f_{z}$. During the precise milling, which is usually carried out with the relatively low depths of cut and feeds, tool's instantaneous displacements can be simultaneously affected by the geometrical errors of machine-toolholder-tool system (e.g. tool run out) and deflections induced by cutting and centrifugal forces.

Preliminary studies involving the measurement of tool displacements in conditions of the executed rotational motion of spindle-tool system revealed that tool's radial run out $e_{r}$ is equal to $15 \mu \mathrm{m}$. Nevertheless, in a majority of investigated cases the maximal measured displacement exceeded the $e_{r}$ value. This observation confirms that displacement is affected also by the tool's elastic deformations induced by the effect of forces.

Figure 3a shows that for the slot milling conditions $(\alpha=0)$, the shape of the displacement time courses are similar to sine function, independently on the selected feed per tooth $f_{z}$ value. However, for the upward ramping strategy $(\alpha>0)$ the displacement signals are less regular and consisting of components with higher frequencies (see - Figs. $3 \mathrm{~b}, \mathrm{c})$. These discrepancies are induced by the distinct tool working angle values, affecting the shape of cutting force time course. During the slot milling, the periodically variable forces are found. On the other hand, in case of upward ramping in finish conditions, the active number of teeth is less than 1 . Thus, the forces are pulsating which consequently affects the shape of tool displacement time course.

The investigated milling parameters (surface inclination angle $\alpha$ and feed per tooth $f_{z}$ ) affect also the tool displacements maximal values (see - Figs. 3 and 4).

It was observed that growth of feed per tooth $f_{z}$ induces the linear increase of displacement peak values (Fig. 4) for the majority of the investigated surface inclinations. According to tool's dynamical deflection model, based on the differential motion equation, the tool deflection amplitudes are proportional to cutting force values, which in turn are usually linearly proportional to feed per tooth. In case of surface inclination angle $\alpha$, the growth of this factor leads to the non-linear decrease of displacement peak values, independently on selected feed per tooth. Moreover, this relation is qualitatively similar to cutting force components curves in function of surface inclination angle (Fig. 5). Typically, the highest force values are obtained during the slot milling because of intense ploughing action induced by the very low cutting speeds located in the area of the tool tip. It should be also 
noted that in case of slot milling, the displacement amplitudes reach up to $140 \mu \mathrm{m}$ and thus exceed the selected feed per tooth values (for $f_{z}=0.05 \mathrm{~mm} /$ tooth and $f_{z}=0.1 \mathrm{~mm} /$ tooth).

a)

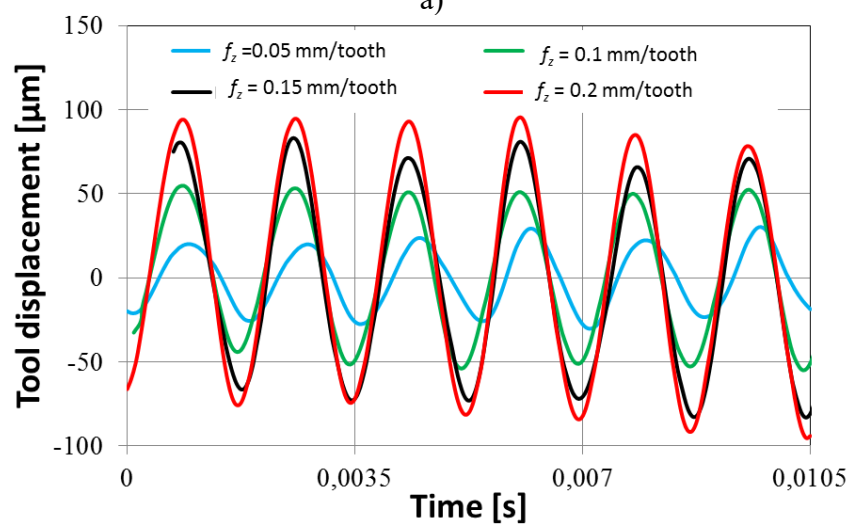

b)

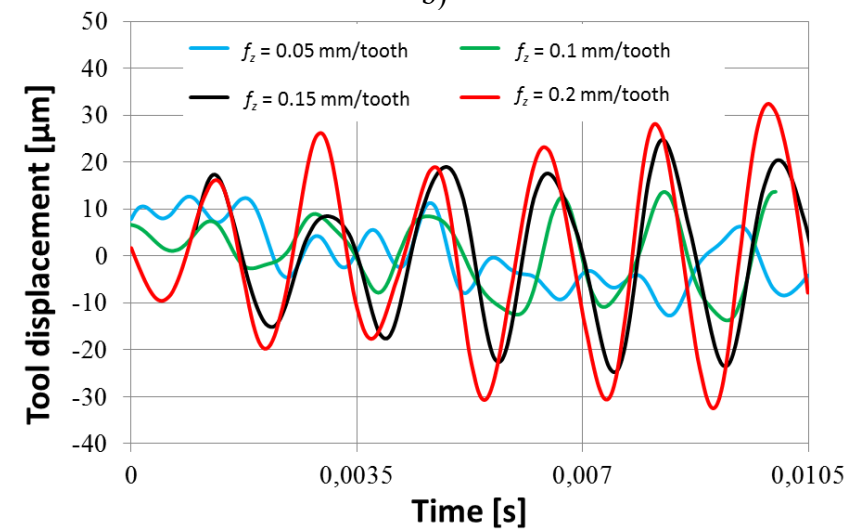

c)

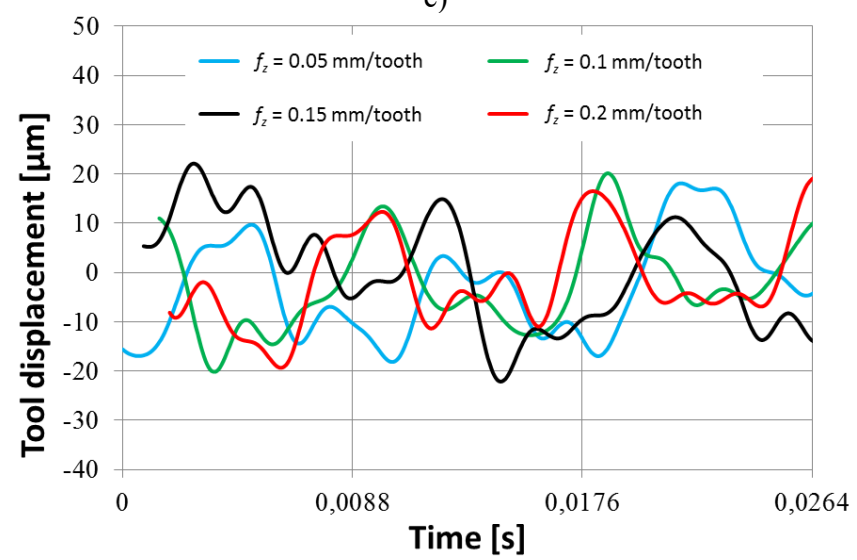

Fig. 3. Instantaneous tool displacements for: a) $\alpha=0$; b) $\alpha=20^{\circ}$; c) $\alpha=60^{\circ}$.

Consequently, the tool can be pushed off from the material which is being currently cut, thereby contributing to the formation of considerable machining errors (e.g. the growth of surface roughness height and/or surface location error). In order to avoid this undesirable phenomenon, the milling process should be carried out at higher surface inclination angles. 

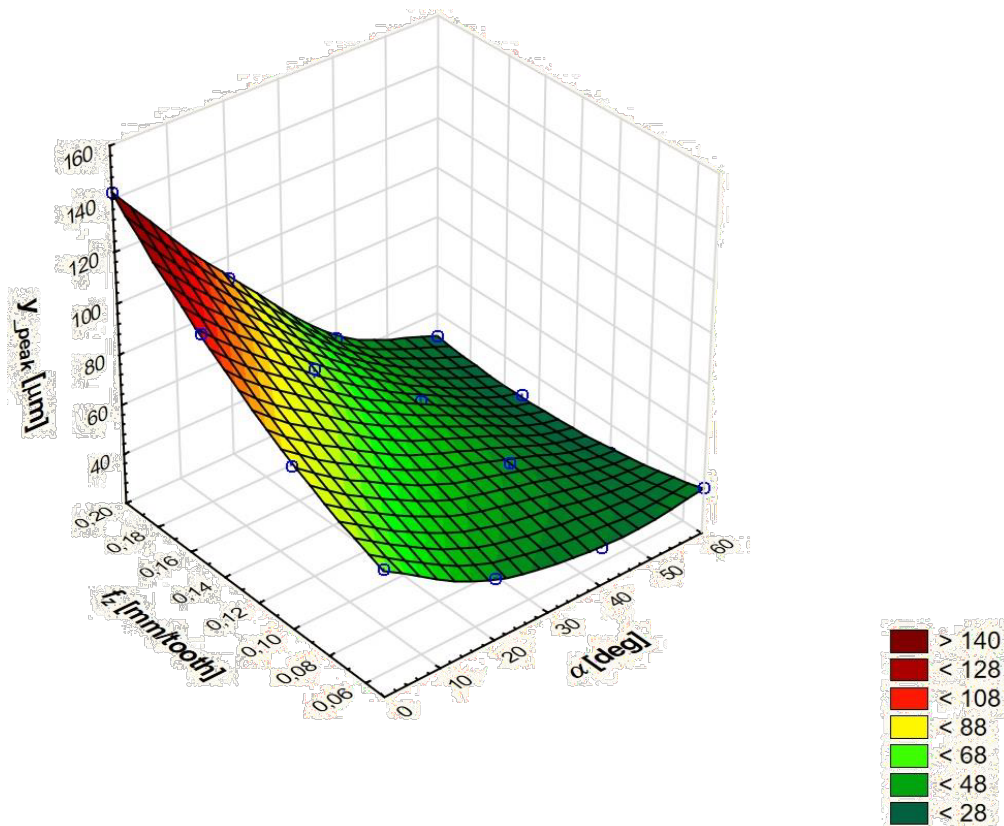

Fig. 4. Ball end mill's displacement peak values in function of surface inclination angle and feed per tooth.

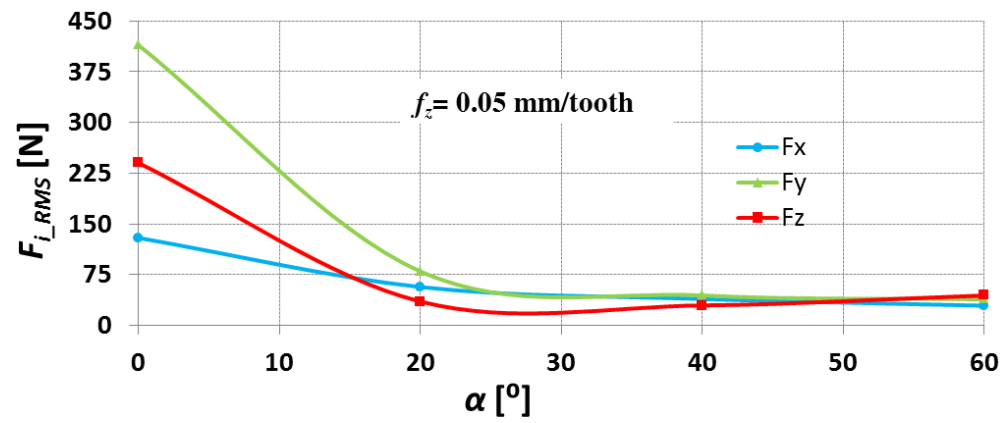

Fig. 5. Cutting force components in function of surface inclination angle.

\section{Conclusions}

On the basis of the carried out investigations, the following conclusions are formulated:

- The surface inclination angle affects the tool displacements qualitatively. In case of slot milling strategy $(\alpha=0)$ the shape of the displacement time course is similar to sine function. However, for the upward ramping strategy $(\alpha>0)$ the displacement curves are less regular and consist of components with higher frequencies;

- The growth of the $\alpha$ angle induces the non-linear decline in maximal displacement values, whereas the increase of $f_{z}$ causes the linear growth of this quantity;

- In terms of tool displacement minimization, the ball end milling process of hardened $55 \mathrm{NiCrMoV} 6$ steel should be carried out with the constant surface inclination angle along the toolpath equaled to $\alpha=60^{\circ}$ and feed per tooth $f_{z}=0.05 \mathrm{~mm} /$ tooth. Thus, the obtained results can be implemented in industry during precise 5-axes ball end milling of a 
complex surfaces, enabling the minimization of surface roughness and surface location errors.

\section{References}

1. R.W. Maruda, G.M. Krolczyk, P. Nieslony, S. Wojciechowski, M. Michalski, S. Legutko, Journal of Manufacturing Processes, 241 107-115 (2016)

2. R. Rusinek, M. Wiercigroch, P. Wahi, Procedia CIRP, 31, 429-434 (2015)

3. D. Przestacki, P. Szymanski, S. Wojciechowski, Composites Part A: Applied Science and Manufacturing, 91 1, 370-379 (2016)

4. S. Wojciechowski, R.W. Maruda, P. Nieslony, G.M. Krolczyk, International Journal of Mechanical Sciences, 119, 360-369 (2016)

5. S. Wojciechowski, P. Twardowski, Procedia CIRP, 1, 289 - 294, (2012)

6. L.N. López de Lacalle, A. Lamikiz, J.A. Sanchez, M.A. Salgado, International Journal of Advanced Manufacturing Technology, 24 621-631 (2004)

7. S. Wojciechowski, P. Twardowski, M. Pelic, Procedia CIRP, 14113 - 118 (2014)

8. T.L. Schmitz, J. Couey, E. Marsh, N. Mauntler, D. Hughes, International Journal of Machine Tools \& Manufacture 47, 841-851 (2007)

9. S. Wojciechowski, Metrology and Measurement Systems, 18, 3, $429-440$ (2011)

10. X. Chen, J. Zhao, Y. Li, S. Han, Q. Cao, A. Li, Int J Adv Manuf Technol, 59 885-898 (2012)

11. K. Tatar, P. Gren, International Journal of Machine Tools \& Manufacture, 48, p. $380-387$ (2008)

12. S. Wojciechowski, P. Twardowski, M. Pelic, R.W. Maruda, S. Barrans, G. Krolczyk, Precision Engineering, 46 158-165 (2016)

13. T. Miyaguchi, M. Masuda, E. Takeoka, H. Iwabe, Precision Engineering, 25, 145-154 (2001) 
